Querstret \& Cropley. Journal of Occupational Health Psychology, in press.

\title{
Exploring the relationship between work-related rumination, sleep quality and work-related fatigue.
}

\section{Dawn Querstret}

School of Psychology, University of Surrey

d.querstret@surrey.ac.uk

\section{Mark Cropley}

School of Psychology, University of Surrey

mark.cropley@surrey.ac.uk

Objective: This study examined the association between three conceptualisations of work-related rumination (affective rumination, problem-solving pondering and detachment) with sleep quality and work-related fatigue. It was hypothesised that affective rumination and poor sleep quality would be associated with increased fatigue; and problem-solving pondering, and detachment would be associated with decreased fatigue. The mediating effect of sleep quality on the relationship between work-related rumination and fatigue was also tested. Method: An on-line questionnaire was completed by a heterogeneous sample of 719 adult workers in diverse occupations. Results: The following variables were entered as predictors in a regression model: affective rumination, problem-solving pondering, detachment, and sleep quality. The dependent variables were chronic work-related fatigue (CF) and acute work-related fatigue (AF). Affective rumination was the strongest predictor of increased CF and AF. Problem-solving pondering was a significant predictor of decreased CF and AF. Poor sleep quality was predictive of increased CF and AF. Detachment was significantly negatively predictive for AF. Sleep quality partially mediated the relationship between affective rumination and fatigue; and between problem-solving pondering and fatigue. Conclusions: Work-related affective rumination appears more detrimental to an individual's ability to recover from work than problem-solving pondering. In the context of identifying mechanisms by which demands at work are translated into ill-health, this appears to be a key finding; and suggests that it is the type of work-related rumination, not rumination per se, that is important.

Keywords: work-related rumination, fatigue, sleep, recovery, work-related stress.

\section{Introduction}

Even though there are many contributing factors underlying the relationship between work-related stress and ill-health, perhaps the most critical mechanism is inadequate psychological and physical recovery (Fritz, Sonnentag, Spector \& McInroe, 2010). Research has shown that inadequate recovery outside of work is associated with a number of poor health outcomes including: increased risk of cardiovascular disease 
(Suadicani, Hein, \& Gyntelberg, 1993), negative mood (Pravettoni, Cropley, Leotta, \& Bagnara, 2007), sleep problems and fatigue (Cropley, Dijk, \& Stanley, 2006; Akerstedt, Fredlund, Gillberg, \& Jansson, 2002; Nylen, Melin, \& Laflamme, 2007).

The process of recovery is often conceptualised in the context of two well-known psychological theories. The Effort-Recovery theory (Meijman \& Mulder, 1998) suggests that people must invest mental and physical resources to deal with work-related demands. This investment results in a depletion of resources and a need to 'recover'; however, recovery will only occur if the depleted systems are no longer taxed (Meijman \& Mulder, 1998; Sluiter, van der Beek \& Frings-Dresen, 1999). The Conservation of Resources Theory (Hobfoll, 1998) proposes that individuals strive to obtain, retain and protect their resources, which can be external (e.g., objects, financial assets) or internal (e.g., personal characteristics or energies). When an individual experiences stress their resources are threatened and in order for recovery to take place new resources must be gained and those that have been lost must be restored (Sonnentag \& Fritz, 2007). Therefore, the Effort-Recovery and Conservation of Resources theories suggest two complimentary processes through which recovery is achieved: firstly, by refraining from demands and activities which tax depleted resources; and secondly, by gaining new internal resources such as energy which will help to restore threatened resources (Sonnentag \& Fritz, 2007).

Importantly, people appear able to cope with the demands of work as long as a consistent level of recovery between periods of work activity can be achieved (de Croon, Sluiter \& Frings-Dresen, 2003; Sluiter, de Croon, Meijman, \& Frings-Dresen, 2003); with intermittent stress followed by complete recovery thought to build physiological 'toughness' (Winwood, Bakker, \& Winefield, 2007). Physiological 'toughness' is associated with low sympathetic nervous system arousal base rates, and responsiveness to stress such that sympathetic arousal is strong only when required (Winwood et al., 2007). However, prolonged or repeated stress exposure with sustained arousal appears to result in damaging health effects (Brosschot, Gerin, \& Thayer, 2006); with persistent failure to unwind after work purported to damage an individual's health because it wears down the body's resilience systems (McEwen, 1998).

If an individual is unable to recover adequately, they may experience fatigue. Given the increased intensity of work environments, fatigue is a common, almost universal, feature of modern life (Dawson, Noy, Harma, Akerstedt, \& Belenky, 2011). The term fatigue is used in many different areas and currently there is no single definition; however, the literature distinguishes between acute and chronic fatigue (Dawson et al., 2011). Acute fatigue is short-lived and signals that the individual needs recovery (e.g., the fatigue an individual experiences at the end of their working day); in contrast, chronic fatigue is persistent and develops as a result of consistent exposure to stress without adequate recovery (Winwood et al., 2007). Research suggests that between $11 \%$ and $30 \%$ of 
workers in Europe are affected by work-related fatigue (Akerstedt et al., 2002; Houtman, 1997; Loge, Ekeberg, \& Kaasa, 1998; Bultmann, Kant, van Amelsvoort, van den Brandt, \& Kasl, 2001); in the USA abnormal fatigue levels have been identified among $14.3 \%$ of men and $20.4 \%$ of women (Chen, 1986); and in Canada similar levels have also been reported (Winwood et al., 2007).

Fatigue affects psychomotor and cognitive functions as well as mood and motivation (Williamson, Lombardi, Folkard, Stutts, Courtney \& Connor, 2011); and it has been linked to decreased vigilance (ability to detect and respond to unpredictable events), reaction times, memory, decision making, information processing, and psychomotor coordination (Lyznicki, Doege, Davis, \& Williams, 1998). The possible consequences of fatigue in the real-world have been well documented (Williamson et al., 2011; Folkard \& Tucker, 2003; Caldwell \& Caldwell, 2005); and there is no doubt that increased levels of fatigue can have serious consequences in the work environment. For example, fatigue in nurses has been implicated in medication errors, decreased productivity, cognitive impairment and increased risk of work-related injuries (Kunert, King \& Kolkhorst, 2007). Research suggests that high work demands and role conflict (Hardy, Shapiro, \& Borrill, 1997); high psychological demands at work, low decision latitude and low social support (Bultmann, Kant, van den Brandt, \& Kasl, 2002; Bultmann, Kant, van Amelsvoort, \& Kasl, 2001), are implicated in causal models of fatigue. However, additional studies are needed to understand the mechanisms by which work-related demands are translated into compromised health and well-being. This article focuses on two possible mechanisms work-related rumination and disturbed sleep - with research suggesting these two mechanisms are predictive of fatigue. For example, Akerstedt, Knutsson, Westerholm, Theorell, Alfredsson, \& Kecklund (2004) examined the multivariate relationship between mental fatigue, work-related factors (work load, work hours), lifestyle factors and disturbed sleep using a Swedish sample of 5720; and found that disturbed sleep and immersion in work (particularly work-related rumination) were most predictive of fatigue.

With increasingly psychologically demanding work environments, one of the factors thought to be critical in the facilitation of adequate recovery is psychological detachment from work, which refers to "an individual's sense of being away from the work situation" (Etzion, Eden, \& Lapidot, 1998, p.579). For psychological detachment to occur individuals need to take a break from thinking about work-related issues. However, one thing people may do when they are not at work is that they may 'ruminate' (think about work-related issues and events). Some people think about tasks they've left uncompleted, others ruminate about a problem that needs to be solved, and still others cogitate about relationship issues with colleagues or negative events at work. People don't just think about events or issues that have already occurred, but they also ruminate anticipatively, about upcoming events/demands and issues they may be expecting at work (Cropley \& Zijlstra, 2011). 
A large proportion of the working population ruminate at one time or another. For example, of 3000 workers interviewed for the Employment Survey of Britain (1992), $72 \%$ reported worrying about their job at some time after work, $22 \%$ described themselves as regular worriers, and $11 \%$ stated they worried about their job after work much of the time (Gallie, White, Cheng, \& Tomlinson, 1998). Furthermore, research suggests that rumination is on the rise (Felstead, Gallie, \& Green, 2002). Rumination is not a new concept. Research in this area has been dominated by clinical/health psychology, with rumination implicated in the aetiology of a number of psychological disorders, e.g., depression and anxiety (Lyubomirsky, Caldwell, \& Nolen-Hoeksema, 1998; Mellings \& Alden, 2000); and associated with increased physical symptom reporting (Hazlett \& Haynes, 1992), intrusive off-task thoughts (Sarason, Pierce, \& Sarason, 1996), negative self-evaluations, diminished feelings of control and feelings of helplessness (Lyubomirsky, Kasri, \& Zehm, 2003). Furthermore, laboratory studies have shown prolonged physiological arousal and delayed recovery in individuals who ruminate (Roger \& Jamieson, 1988).

There is a preoccupation in the literature with conceptualising rumination as a negative process; and the majority of research focuses on repetitive thinking about negative experiences (Pravettoni et al., 2007). On this basis, one may automatically think that rumination is detrimental to recovery; however, rumination does not necessarily need to be a negative experience, and a number of authors have suggested that rumination may be too broad a term. Segerstrom, Stanton, Alden, \& Shortridge (2003) argued that thoughts should not only be distinguished as negative versus positive, but they should also be separated based on their purpose, or focus (i.e. problem-solving versus searching for meaning). Pravettoni et al. (2007) have differentiated between 'repetitive' and 'creative' rumination; and more recently Cropley \& Zijlstra (2011) have differentiated between affective rumination and problem-solving pondering.

For Cropley \& Zijlstra the key difference between the affective and problem-solving states is to do with emotional arousal. In the affective state, psychophysiological arousal remains high and this is not conducive to the recovery process; in contrast, the problemsolving state is proposed to exist without psychological and physiological arousal, therefore it is less damaging for recovery. According to Cropley \& Zijlstra, affective rumination is negatively valenced, whereas problem-solving rumination could potentially be positively valenced, especially if the process of problem-solving pondering results in a solution; a position supported by research suggesting that thinking about successfully completed tasks increases positive affect, self-efficacy and well-being (Seo, Narrett \& Bartunek, 2004; Stajkovic \& Luthans, 1998). Therefore, it is possible that rumination with a problem-solving focus could actually be beneficial to recovery. To the author's knowledge, there is no current research considering the differential effects of different ruminative states on work-related fatigue; however, it seems reasonable to posit that affective rumination may disrupt recovery processes; whereas rumination with a problem- 
solving focus, and psychological detachment (representing an absence of ruminative thinking), may be beneficial to recovery.

Hypothesis 1: Participants reporting higher levels of affective rumination will report higher levels of fatigue.

Hypothesis 2: Participants reporting higher levels of problem-solving pondering will report lower levels of fatigue.

Hypothesis 3: Participants reporting higher levels of psychological detachment will report lower levels of fatigue.

Another factor important in the context of recovery is sleep. The value of good quality sleep for effective recovery is well established (Stewart, Abbey, Meana, \& Boydell, 1998; Singh, Clements, \& Fiatarone, 1997; O'Connor \& Yongstedt, 1995). The brain requires sleep in order for energy stores to be replenished (Porkka-Heiskanen, Kalinchuk, Alanko, Urrila, \& Stenberg, 2003); and research has shown an association between poor sleep and a multitude of different health impairments, such as self-reported coronary heart disease (Schwartz, Anderson, Cole, Cornoni-Huntley, Hays, \& Blazer, 1999), gastrointestinal problems, high blood pressure, and neurological disorders (Taylor, Mallory, Lichstein, Durrence, Riedel, \& Bush, 2007). Performance is also negatively impacted by sleep loss which can result in increased fatigue, mood changes, and impairment of the immune system (Harrison \& Horne, 1999; Rogers, Szuba, Staab, Evans, \& Dinges, 2001). One of the consequences of sleep disturbance is sleepiness during activity periods which can result in an increase in work-related accidents (Lauber \& Kayten, 1988); with potential work-related injuries and loss of productivity (Kantermann, Juda, Vetter, \& Roenneberg, 2010).

The mechanisms by which demands at work interfere with sleep are poorly understood; however, the sleep literature agrees that one of the factors thought to interfere with sleep is rumination, with self-reported sleep disturbance showing a strong relationship with work-related worries (Akerstedt et al., 2002). People who work in demanding environments often complain of sleep disturbance and attribute this to work-related rumination (Berset, Elfering, Luthy, \& Semmer, 2010). Furthermore, many researchers have found significant negative associations between self-reported rumination and sleep quality (Cropley et al., 2006; Thomsen, Mehlsen, Christensen, \& Zachariae, 2003; Thomsen, Mehlsen, Hokland, Viidik, Olesen, Avlund, Munk, \& Zachariae, 2004); and anticipative rumination has been found to be associated with both subjective and objective sleep measures (Kecklund \& Akerstedt, 2004). Experimental studies also provide support for an association between rumination and sleep; e.g., longer sleep onset latency has been observed in high trait ruminators (Zoccola, Dickerson, \& Lam, 2009).

Therefore, it is plausible to consider work-related rumination as an extension of demands at work, and as such, as a proxy for work-related stress. This position has been supported 
by research showing that part of the effect of high work demands can be accounted for by inability to mentally switch off after work (Akerstedt et al., 2004); and by research which showed that rumination about work mediated the relationship between work demands and sleep (Berset et al., 2010). If work-related rumination operates to maintain psychophysiological response to work-related stressors once the individual has left work, it is possible this continued activation interferes with recovery processes by negatively impacting sleep. Conceptually, it is unlikely that rumination directly influences fatigue. Instead, we argue that the impact rumination has on fatigue is realised via its effect on a variable that has a direct relationship with fatigue, namely sleep. It is possible for sleep quality to directly influence levels of fatigue; i.e. if you do not experience restorative sleep, you may experience higher levels of fatigue. Our contention is that rumination influences fatigue by interfering with sleep. No previous study has tested the mediating effect of sleep quality on the relationship between work-related rumination and fatigue. As sleep is one of our most important restorative processes, and there is evidence suggesting that rumination interferes with sleep, it seems plausible that rumination could negatively affect sleep quality, resulting in fatigue.

Hypothesis 4: Participants reporting lower sleep quality will report higher levels of fatigue.

Hypothesis 5(a): Sleep quality will mediate the relationship between affective rumination and chronic fatigue.

Hypothesis 5(b): Sleep quality will mediate the relationship between affective rumination and acute fatigue.

Hypothesis 5(c): Sleep quality will mediate the relationship between problem-solving pondering and chronic fatigue.

Hypothesis 5(d): Sleep quality will mediate the relationship between problem-solving pondering and acute fatigue.

\section{Method}

\section{Design}

Participant completed an online cross-sectional survey.

\section{Pilot study}

A pilot study was run with 10 participants before the study commenced to ensure that questions were appropriate and easily understood, and that the survey did not take longer than 20 minutes to complete.

\section{Sample and participants}

The sample was comprised of 719 working adults ( $M=50.8 \% ; F=49.2 \%)$ with an age range of $19-69$ years $(M=42.91, S D=9.41)$. The majority of participants $(88.7 \%$ [638]) 
worked full-time for a mean of 46.61 hours/week $(S D=7.53)$ in jobs they had held for a mean of 6.99 years $(S D=7.36)$; and 313 participants $(43.5 \%)$ managed others in their role. Five hundred and sixty-nine participants (79.2\%) were married or had a partner, 56 participants $(7.8 \%)$ were separated/divorced or widowed, and 94 participants (13.1\%) were single. Three hundred and thirty participants (45.9\%) reported having dependent children. Four hundred and twenty-three participants (58.8\%) worked a traditional 9am$5 \mathrm{pm}$ (Mon-Fri) pattern, 188 participants $(26.2 \%)$ worked rotating shifts (early, late, and night), and 102 participants (14.2\%) worked a non-standard shift pattern (e.g., long days with no set shift pattern; mix of weekends and day shifts), with the remaining six participants $(0.8 \%)$ working either weekend or night shifts. Participants from emergency services represented $34.8 \%$ (250) of the sample, followed by legal (19.1\% [137]), education (10.3\% [74]), nursing (9.5\% [68]), administration (7.1\% [51]), management $(6.5 \%[47])$, other $(4.2 \%[31])$, medicine (3.9\% [28]), human resources $(2.9 \%[21])$, and healthcare $(1.7 \%$ [12]). The majority of participants were University educated (57.5\% [414]), or had completed their high school education or equivalent $(41.8 \%$ [301]), with only 4 participants $(0.6 \%)$ stating they had no formal qualifications.

\section{Procedure}

Ethical approval was granted by the Faculty of Arts \& Human Sciences Ethical Committee at the University of Surrey. To recruit participants, as a first step, organisations affiliated with the University of Surrey through a 'Recovery from work' research group were approached by email and invited to take part in the study. These public and private sector organisations span multiple industries including: pharmaceuticals, media, energy, banking, education, emergency services and healthcare.

It was explained that a study was being conducted with the aim of understanding how adults recover when not at work, and the different factors that may interfere with this process of recovery. An electronic link to an online survey was sent to organisations who agreed to take part, and they then forwarded this link to their employees. An article was written for a professional journal to encourage participation from nursing and other medical staff, and a link to the online survey was included with the article (Querstret \& Cropley, 2011); and also with an accompanying web article (Querstret, 2011). Furthermore, details of the study and a live link to the survey were posted on social networking sites to encourage participation of any individuals who were over 18 years of age and working. Individuals who chose to participate were encouraged to circulate the link to family and friends who were over 18 years of age and working. In this way, it was hoped to increase participation by a "snowballing" effect (Winwood et al., 2007).

\section{Measures}

Work-Related Rumination

The Work-Related Rumination Questionnaire (WRRQ) is a new self-report measure designed to measure a proposed three-factor model of perseverative thinking about work 
(Cropley, Michalianou, Pravettoni, \& Millward, 2012). It is comprised of three subscales, each with 5-items: affective rumination, problem-solving pondering and detachment. Included in the affective rumination subscale are items such as, "Are you troubled by work-related issues when not at work?"; an item representative of the problem-solving pondering subscale is, "After work I tend to think about how I can improve my performance"; and the detachment subscale includes items such as, "I am able to stop thinking about work-related issues in my free time". Items are responded to against a 5point likert scale ranging from $1=$ "Very seldom/never" to $5=$ "Very often/always", and each subscale yields a total score which ranges from 0 to 25 . The detachment subscale has been shown to be strongly and negatively correlated with both the affective rumination and problem-solving pondering subscales (Cropley et al., 2012). Confirmatory factor analysis supported each of the three conceptualized factors; and together they accounted for $68.4 \%$ of the variance. Cronbach's alphas for the present study $=.90$ (affective rumination), .81 (problem-solving pondering), and .88 (detachment).

\section{Fatigue}

The Occupational Fatigue Exhaustion Recovery scale (OFER) is a 15-item measure that has been validated in several studies as a measure of work-related fatigue (Winwood et al., 2007; Winwood, Lushington, \& Winefield, 2006; Winwood, Winefield, Dawson, Lushington, 2005). It is comprised of three subscales of five items each which represent chronic fatigue (CF), acute fatigue (AF), and inter-shift recovery (ISR) respectively. Typical items for CF include, "I often dread waking up to another day of my work"; and items included on the AF subscale include, "After a typical work period, I have little energy left". Each item is responded to on a seven point likert scale ranging from $0=$ "Completely disagree" to $6=$ "Completely agree". Each subscale yields a total score that ranges from 0-100. Cronbach's alphas for the present study =.91 (CF), .93 (AF). Due to the focus of this article, the ISR subscale was not analysed.

\section{Pittsburgh Sleep Quality Index}

The Pittsburgh Sleep Quality Index (PSQI) is a validated questionnaire comprised of 19 items assessing sleep quality and disturbances over a one-month interval (Buysse, Reynolds III, Monk, Berman, \& Kupfer, 1988). These 19 items result in seven component scores (subjective sleep quality, sleep latency, sleep duration, habitual sleep efficiency, sleep disturbances, use of sleep medication, and daytime dysfunction) which are summed together to yield a global PSQI score, ranging from 0 to 21 . A score $>5$ indicates poor sleep quality (Buysse et al., 1988). Cronbach's alpha for this scale has been reported to be 0.83 (Buysse et al., 1988; Carpenter \& Andrykowski, 1988).

\section{Control variables}

Single items were included in the survey for gender ( $1=$ female; $2=$ male), age, dependent children ( 1 =yes, $2=$ no), work status ( $1=$ full-time, 2 =part-time, $3=$ temporary worker, $4=$ self-employed), work pattern ( $1=9 \mathrm{am}-5 \mathrm{pm}$ [Mon-Fri], $2=$ rotating shifts, $3=$ night work, 
$4=$ weekend work) and hours worked per week. The reason for controlling for demographic data (i.e. gender, age, dependent children) was that women or people with children may differ in their ability to properly recover when not at work, due to duties at home or the requirements of child care. Additionally, older people may have more difficulties recovering adequately than younger people who may engage in active recovery processes. Hours worked per week and work status may have an influence over fatigue levels as those working longer hours may have fewer opportunities for recovery. Work pattern may influence fatigue as those working shifts may find it more difficult to recover than those working a traditional pattern.

Because negative affect (NA) may bias responses in survey studies (Brief, Burke, George, Robinson, \& Webster, 1988), and could therefore influence how people judge their level of fatigue, we included it as a control variable. Negative affect was assessed using 10 items of the Positive and Negative Affect Schedule (PANAS; Watson, Clark, \& Tellegen, 1988). Items were single words representing different emotions associated with NA; for example, "Distressed", "Guilty", and "Irritable". Respondents rate the extent to which they have experienced a particular emotion (during the past month) against a 5-point likert scale ranging from $1=$ "Very slightly or not at all" to $5=$ "Extremely". A total score for NA is yielded, with higher scores representing greater affect. Cronbach's alpha in the present study $=.89$. The PANAS is a widely used scale which has been validated in occupational health settings (Kortte, Gilbert, Gorman, \& Wegener, 2010).

Whilst this study was focussed on the relationship between work-related rumination, sleep and fatigue; we felt it was important to control for other measurable variables which theoretically, and on the basis of existing research, could also be related to fatigue. For example, research based on the Demand-Control model (Karasek \& Theorell, 1990) has shown that high job demands and low levels of control at work are associated with increased strain and psychophysiological complaints (de Lange, Taris, Kompier, Houtman \& Bongers, 2003; Van der Doef \& Maes, 1999). In the context of the Effort Recovery Theory, increased job demands interfere with recovery processes by reducing the time available to the individual; and limited control at work can damage recovery because individuals may be required to continue expending effort at times when they require a break psychologically and physiologically. As such, both low control at work and high levels of demand at work can compromise opportunities for recovery (Sluiter et al., 2003), potentially resulting in fatigue. We included measures to assess job demands, job control and recovery opportunities to control for their impact on fatigue, thereby affording us a clearer picture of the unique contribution of the variables of interest, namely affective rumination, problem-solving pondering and sleep quality.

Job demands and job control

Job control and job demands were measured by including relevant items from the Job Content Questionnaire (JCQ; Karasek, Brisson, Kawakami, Houtman, Bongers, \& Amick, 
1988). Ten items were used to measure perceived job demands, including items, "Do you have to work very fast?"; and ten items were used to measure perceived job control, including items such as, "Do you have a choice in deciding HOW you do your work?". Each item was responded to on a 4-point likert scale ranging from $1=$ "Never/Almost never" to $4=$ "Often". For each of these scales, items are summed to yield a total score which ranges from 10 to 40, with high scores indicating high job demands, or high job control, respectively. Cronbach's alphas for the present study $=.78$ (job demands) and .86 (job control). This is a widely used measure that has been validated in occupational health settings (Kuper \& Marmot, 2003).

Opportunities for recovery

Opportunities for recovery were measured using the Opportunities for Recovery Scale which was developed to measure opportunities for recovery both within and outside of the work context (van Veldhoven \& Sluiter, 2009). Items included on the scale include, "Can you interrupt your work if you find it necessary to do so?". The scale is comprised of 9 items which are responded to on a 4-point likert scale ranging from $0=$ "Never" to $3=$ "Always". The scale yields a total score ranging from 0-18. Cronbach's alpha for the present study $=.85$. Cronbach's alpha for this scale has been reported in three previous study samples at .70, .75, and .77 (van Veldhoven \& Sluiter, 2009).

\section{Results}

Four participants identified themselves as suffering from chronic fatigue syndrome so the analyses were run once with them and then again without them. As their inclusion made no difference to the results, they were included in the analyses. One of the items in the affective rumination scale references fatigue ("Do you become fatigued by thinking about work-related issues during your free time?"), so the results were run once with this item included in the affective rumination measure and once without it included. As the unique variance for affective rumination appeared to be inflated both for chronic fatigue and for acute fatigue with the item included, it was removed from the affective rumination measure and the remaining 4-items were used in the analysis (Cronbach's alpha $=.87$ ).

All statistical analyses were performed using PASW 18 (SPSS, 2009). Before conducting the main analyses, the data were tested for the presence of outliers, normality, and linearity (Field, 2009). Due to the size of the sample $(N=719)$ statistical tests of normality (e.g., skewness, kurtosis, Shapiro wilk) were not appropriate. This is because even small deviations from normality will produce a highly significant statistic in large samples (Field, 2009). Instead, we reviewed histograms for all variables and confirmed visually their normal distribution. Furthermore, when running the regression analyses, we reviewed the distribution of residuals for the dependent variables (acute fatigue; chronic fatigue) and confirmed normality this way. Means, standard deviations and ranges for all variables can be viewed in Table 1. 
[Insert table 1 about here]

\section{Correlation analysis}

The data were analysed using Pearson's Product Moment Correlation Coefficient. To account for multiple comparisons, a bonferroni correction was applied, and significance was evaluated against an alpha level of $p<.001$ (Miller, 1984). Analysis of the correlation matrix revealed that the relationships between affective rumination, detachment, sleep quality and acute and chronic fatigue, were all significant and in the direction predicted by hypotheses 1,3 and 4 (respectively). The significant positive relationship between problem-solving pondering and the two fatigue outcomes was not in the direction predicted by hypothesis 2; however, further analysis revealed that problem-solving pondering meets the criteria of a suppressor variable (Cohen \& Cohen, 1975). Its effects will be explained in the results section and interpreted in the discussion. Identification of potential confounds was undertaken by reviewing the correlations between the proposed control variables (gender, age, dependent children, work status, work pattern, hours worked per week, job demands, job control, recovery opportunities and negative affect) and the outcome variables (chronic fatigue and acute fatigue). As age, work status, work pattern, dependent children and hours worked per week were not significantly correlated with the outcome variables; they were not included as control variables in further analyses. Gender, negative affect, job demands, job control, and recovery opportunities were controlled in further analyses as they were significantly correlated with both outcome variables. All correlations can be viewed in Table 2 .

\section{[Insert table 2 about here]}

\section{Multiple regression analyses}

Hypotheses 1, 2, 3, and 4 were tested using a multiple regression approach in which the control variables (gender, negative affect, job demands, job control, and recovery opportunities) were entered in Step 1; and the predictor variables (affective rumination,

problem-solving pondering, detachment, and sleep quality) were entered in step 2 . The results for chronic fatigue are displayed in Table 4; the results for acute fatigue are displayed in Table 5. To test for multicollinearity, variance inflation factor (VIF) and tolerance statistics were assessed and all variables were within acceptable limits (i.e., VIF $<10$; tolerance $>.1$; Field, 2009); therefore multicollinearity did not bias the regression models.

Table 3 shows that the control variables accounted for $19.33 \%$ of the variance in chronic work-related fatigue (CF); and that, with the exception of job demands, all of the control variables were significant predictors. The predictor variables entered in step 2 contributed significantly to the prediction of CF. Affective rumination ( $9 \%$ of the unique variance) and sleep quality ( $1 \%$ of the unique variance) showed significant positive relationships with 
$\mathrm{CF}$; and problem-solving pondering ( $1 \%$ of the unique variance) was a significant negative predictor of CF. Detachment was not a significant predictor of CF.

[Insert table 3 about here]

Table 4 shows that the control variables - which were all significant predictors - accounted for $18.5 \%$ of the variance of acute work-related fatigue (AF). The predictor variables entered in step 2 contributed significantly to the prediction of AF. Affective rumination ( $3 \%$ of the unique variance), and sleep quality $(2.2 \%$ of the unique variance) showed significant positive relationships with AF. Detachment and recovery opportunities showed significant negative relationships with AF.

\section{[Insert table 4 about here]}

The negative association of problem-solving pondering with both fatigue variables in the respective regression results, when considered in the context of its positive association with both fatigue variables in the correlation table, identify it as a suppressor variable (Cohen \& Cohen, 1975) within the data. In order to establish which of the variables problem-solving pondering was interacting with, we systematically removed each variable from the model and reran the regression analysis with each of the resultant reduced models. The only variable that reduced the negative predictive power of problem-solving pondering when it was removed from the model was affective rumination. Problemsolving pondering and affective rumination are positively related in the correlation table and they are both positively related to the chronic and acute fatigue. However, when they are entered into a regression equation together, problem-solving pondering takes on a negative sign. According to Pandey \& Elliott (2010), problem-solving pondering meets the criteria of a negative suppressor variable. It's inclusion in the regression equation clarifies the relationship between affective rumination and the two forms of fatigue. It does this by removing error variance, which is shared by problem-solving pondering and affective rumination, from the model. Our detailed interpretation of these results will be addressed in the discussion.

In summary, affective rumination was the strongest predictor of both fatigue outcomes, accounting for $9 \%$ of the unique variance in $\mathrm{CF}$ and $3 \%$ of the unique variance in $\mathrm{AF}$. Problem-solving pondering was a significant predictor of decreased CF and AF. Poor sleep quality was predictive of higher levels of CF and AF. Hypotheses 1 and 4 were fully supported. We contend that hypothesis 2 has been partially supported because of the incongruence of the the positive zero-order correlation between problem-solving pondering and the two fatigue outcomes in the correlation table; against the negative relationship between problem-solving pondering and the two fatigue outcomes in the regression equations. Our position is that the correlation table presents an incomplete picture of the relationship between variables; and that the regression equation reflects 
more accurately the relationship between problem-solving pondering and fatigue (Pandey \& Elliott, 2010). However, we cannot conclude that hypothesis 2 has been fully supported on this basis. Hypothesis 3 was partially supported as detachment was negatively predictive of $\mathrm{AF}$ but not $\mathrm{CF}$.

\section{[Insert figure 1 about here]}

\section{Testing for mediation}

To establish mediation, four steps must be satisfied (Baron \& Kenny, 1986; Judd \& Kenny, 1981). Step 1: The predictor variable (work-related rumination) should be correlated with the outcome variable (fatigue) as this establishes that there is a direct effect to be mediated (pathway c , Figure 1). Step 2: Work-related rumination should be correlated with the mediator (sleep quality; pathway $\mathbf{a}$, figure 1 ). Step 3: Sleep quality should affect fatigue (pathway $\boldsymbol{b}$, figure 1). Step 4: A regression equation is performed with both sleep quality and work-related rumination as predictors of fatigue. If work-related rumination no longer affects fatigue after sleep quality has been controlled a model of complete mediation has been supported. If work-related rumination continues to affect fatigue once sleep quality is controlled, a model of partial mediation would be supported. However, these four steps alone do not establish mediation; it is also prudent to provide a statistical test of the significance of the indirect pathway, or the mediation effect. Baron and Kenny (1986) recommend testing the significance of the indirect path $(\boldsymbol{a} \times \boldsymbol{b}$, figure 1$)$ by the Sobel z-test shown in the equation below (or variants).

$$
z=\frac{a \times b}{\sqrt{b^{2} s_{a}^{2}+a^{2} s_{b}^{2}}}
$$

The Sobel z-test assesses whether the difference between the total effect and the direct effect is statistically significant. Because our sample size was large $(N=719)$, we utilised the Sobel Z test as per Baron \& Kenny's (1986) recommendation (c.f. Zhao, Lynch, \& Chen, 2010).

As there were two measures of work-related rumination in the study (affective rumination and problem-solving pondering), and there were also two fatigue outcomes (CF and AF), four separate mediation tests were performed. Mediation tests one and two ascertained whether sleep quality mediated the relationship between affective rumination and $\mathrm{CF}$, or affective rumination and $A F$, respectively. Mediation tests three and four tested whether sleep quality mediated the relationship between problem-solving pondering and $\mathrm{CF}$, or problem-solving pondering and $\mathrm{AF}$, respectively. 


\section{Mediation tests}

For all four mediation hypotheses $(5(a) ; 5(b) ; 5(c) ; 5(d))$, the first mediation step was supported because both forms of work-related rumination - affective rumination and problem-solving pondering - were significantly correlated with both CF and AF. For all four hypotheses, Step 2 was supported as sleep quality was significantly correlated with affective rumination, and with problem-solving pondering; i.e., higher levels of affective rumination and problem-solving pondering were associated with decreased sleep quality. For all four hypotheses, Step 3 was also supported as sleep quality was significantly associated with both CF and AF; with poorer sleep quality (higher scores on the PSQI) associated with higher reported levels of CF and AF.

For hypotheses 5(a) and 5(b), a full mediation model was not supported because affective rumination remained a significant predictor of $\mathrm{CF}$, and of $\mathrm{AF}$, once sleep quality was controlled. However, the results support a partial mediation model for both hypotheses because the addition of sleep quality to the model reduced the beta of affective rumination for both fatigue outcomes. Furthermore, the Sobel z-test was significant indicating that sleep quality mediated the relationship between affective rumination and CF $(z=6.1921, p<.001) ;$ and also between affective rumination and AF ( $z=6.5350$, $\mathrm{p}<.001)$. Table 5 shows test results for the mediation effect of sleep quality on the relationship between affective rumination and the two fatigue outcomes.

\section{[Insert table 5 about here]}

For hypotheses 5(c) and 5(d), Step 3 was supported as problem-solving pondering was significantly associated with $\mathrm{CF}$, and also with $\mathrm{AF}$; i.e., higher levels of problem-solving pondering were associated with decreased levels of CF and AF. A full mediation model was not supported because problem-solving pondering remained a significant predictor of CF, and of AF, once sleep quality was controlled. However, the results support a partial mediation model for both hypotheses because the addition of sleep quality to the model reduced the beta of problem-solving pondering for both fatigue outcomes. Furthermore, the Sobel z-test was significant indicating that sleep quality mediated the relationship between problem-solving and $\mathrm{CF}(z=3.6014, p<.001)$; and also between problem-solving pondering and $\operatorname{AF}(z=3.5990, p<.001)$. Table 6 shows test results for the mediation effect of sleep quality on the relationship between problem-solving pondering and the two fatigue outcomes.

\section{[Insert table 6 about here]}

In summary, sleep quality partially mediated the relationship between affective rumination and both fatigue outcomes, and problem-solving pondering and both fatigue outcomes; therefore, the four mediation hypotheses ( $5(a), 5(b), 5(c), 5(d)$ ) were partially supported. 


\section{Discussion}

This study addressed the relationship between work-related rumination, sleep quality and fatigue. It was hypothesised that affective rumination and poor sleep quality would be predictive of increased levels of fatigue (hypotheses $1 \& 4$ ), and that problem-solving pondering and psychological detachment would be predictive of decreased levels of fatigue (hypotheses $2 \& 3$ ). Hypotheses 1 and 4 were fully supported; hypothesis 2 and 3 were partially supported. Additionally, the mediating effect of sleep quality on the relationship between affective rumination and fatigue, and problem-solving pondering and fatigue, was explored. Sleep quality partially mediated the relationship between affective rumination and both forms of fatigue, and also partially mediated the relationship between problem-solving pondering and both forms of fatigue. Therefore, hypotheses 5(a), 5(b), 5(c) and 5(d) were partially supported.

The major finding of this study was that affective rumination was the most significant predictor of both acute and chronic fatigue, in both cases accounting for the largest amount of unique variance. In fact, affective rumination accounted for $9 \%$ of the unique variance in chronic fatigue, and for $3 \%$ of the unique variance in acute fatigue, suggesting it is a significant factor in the context of work-related fatigue. In line with the EffortRecovery theory (Meijman \& Mulder, 1998), it's possible that affective work-related rumination continues to tax those systems engaged during work-time, thereby operating to extend work-related demands and maintain psychophysiological arousal.

However, the findings are also suggestive that the two types of work-related rumination may operate differentially on recovery processes; specifically, it appears that problemsolving pondering may be less detrimental to recovery than affective rumination. This finding is interesting as this was hypothesised on the basis of theory (Cropley \& Zijlstra, 2011), with little pre-existing research to draw on. However, Pravettoni et al. (2007) investigated the process of recovery from fatigue, and hypothesised that ruminative processes would be different for different types of workers. They differentiated between industrial workers and knowledge workers positing that industrial workers engaged in more 'repetitive' rumination - which tended to be focussed on past events, and was negatively valenced - whereas knowledge workers (who work in more psychologically demanding environments) engaged in more 'creative' rumination which was focussed on future events, and could potentially be a positive experience. Whilst this study did not focus on the different ruminative styles of different occupational groups, the findings here do suggest there may be different ruminative styles or processes. There was a clear delineation between affective rumination and problem-solving pondering and these two styles of rumination appeared to operate differentially on recovery processes.

As stated earlier, the changing sign of problem-solving pondering from positive in the correlation table, to negative in the regression equation, identified it as a suppressor variable (Cohen \& Cohen, 1975). Ironically, suppressor variables may more accurately be 
named 'enhancers' because they suppress the 'noise' they share with one (or multiple) predictors and therefore clarify relationships between predictors and outcome variables, increasing the predictive power of the regression model (Pandey \& Elliott, 2010). We contend that the positive variance shared between affective rumination and problemsolving pondering reflects the fact that sometimes people who ruminate with a problemsolving focus will also have an emotional response (which is fundamental to affective rumination). For example, it may be that a solution does not present itself and frustration occurs which could then invoke a similar psychophysiological response as we hypothesise is integral to affective rumination.

However, the fact that affective rumination and problem-solving rumination, when present in the regression equation together, operate differentially on the fatigue outcome, highlights that there is also an important conceptual difference between them. Problemsolving pondering and affective rumination clarify each other's relationship with fatigue by reducing the irrelevant shared variance (or noise) in the regression model. If either of these variables was removed from the model, this would present an incomplete picture of the relationship of the two types of rumination to fatigue. This highlights the importance of ensuring suppressor variables are included in multiple regression models because they improve the explanatory power of the model and remove irrelevant shared 'noise' between predictor variables (Pandey \& Elliott, 2010). Our considered position is that while both forms of rumination can interfere with recovery, it is when problem-solving ruminators also have an emotional response that recovery is most compromised. We assert therefore that affective rumination is more detrimental to recovery than problemsolving pondering.

What could be the reason for this differential effect on recovery? One possibility is that the different types of work-related rumination may differentially activate the sympathetic and parasympathetic nervous systems. The negatively-valenced, emotion-focused orientation of affective work-related rumination may mean that it is similar to clinical rumination. Clinical rumination has been implicated in the aetiology and maintenance of a number of psychological disorders, e.g., depression \& anxiety (Lyubomirsky et al., 1998; Mellings \& Alden, 2000); and research suggests that it has the effect of taking the prefrontal cortex temporarily "off-line" (Ottaviano, Shapiro, Davydov, Goldstein, \& Mills, 2009). The prefrontal cortex normally exerts inhibitory control over excitation of the sympathetic nervous system; and clinical rumination appears to disinhibit these circuits, resulting in parasympathetic withdrawal and relative dominance of the sympathetic system (Brosschot, van Dijk, \& Thayer, 2007). Therefore, it could be that affective workrelated rumination bypasses prefrontal systems maintaining sympathetic arousal. This position appears to be supported by research showing that high trait rumination is associated with increased levels of salivary cortisol secretion, which is a physiological marker for stress response (Rydstedt, Cropley, Devereux, \& Michalianou, 2009). 
In contrast, problem-solving pondering may be operating via the prefrontal cortex, thereby dampening the psychophysiological response and engaging the parasympathetic system. This has intuitive appeal because problem-solving pondering involves finding solutions to work-related problems; therefore, it follows that areas of the brain involved in planning and executive function (e.g., prefrontal cortex) would be activated. Another possibility is that problem-solving pondering operates protectively because the individual finds a solution to a problem, thereby concluding the ruminative process; whereas affective rumination offers no such relief. Martin \& Tesser (1996), in their self-regulation model of ruminative thought, suggest there are three mechanisms by which ruminative thinking can be stopped: distraction, disengagement from the goal, and goal attainment. In the context of this theory, problem-solving pondering may satisfy a requirement for goal attainment (if a solution is arrived at), offering a sense of achievement and satisfaction for the individual. This would align with the findings of previous studies suggesting that reflecting on completed tasks has been shown to increase positive affect, self-efficacy and well-being (Seo et al., 2004; Stajkovic \& Luthans, 1998).

Compromised sleep quality was also a significant predictor of both acute and chronic fatigue. This result was expected and in line with previous research suggesting that impaired sleep is implicated in compromised recovery (Stewart et al., 1998; Singh et al., 1997; O'Connor \& Youngstedt, 1995). However, it is not clear what aspects of sleep quality are most predictive of fatigue and further analysis is planned to investigate this in more detail. For example, if the sleep quality measure is broken down into its component parts for analysis, it will be possible to explore specifically which of the components (e.g., delayed sleep onset; interrupted sleep; duration of sleep) is most predictive. The use of a composite measure for sleep quality may also explain the finding of only a partial mediation effect of sleep quality on the relationship between work-related rumination and fatigue. Whilst this partial mediation finding aligns with research suggesting rumination interferes with sleep (Cropley et al., 2006; Thomsen et al., 2003; Thomsen et al., 2004; Zoccola et al., 2009; Harvey, Tang, \& Browning, 2005); it would be interesting to examine if one or more of the specific sleep quality components mediates completely the relationship between work-related rumination and fatigue. For example, recent research suggests that the way in which rumination interferes with sleep is by delaying sleep onset (Zoccola et al., 2009). The fact that the direct relationship between work-related rumination and fatigue remained significant even when controlling for sleep quality indicates that there are other, as yet unexplored, mediator variables to be considered.

The relationship between sleep quality and fatigue is difficult to interpret. One reason for this is that while sleep quality can be considered a predictor of fatigue, it may also be compromised as a result of fatigue, e.g., non-refreshing sleep is a symptom of chronic fatigue syndrome (Van't Leven, Zielhuis, van der Meer, Verbeek, \& Bleijenberg, 2009). Because of the cross-sectional nature of the data causality between variables cannot be established (Field, 2009). Therefore, it is not possible to be sure of the direction of the 
relationship between sleep quality and fatigue. While the interpretation that poor sleep quality predicts fatigue is one possibility, it is also possible that the direction of causality is reversed.

\section{Practical implications}

There are practical implications for organisations to consider. Often, organisations believe that their responsibility for employee health and well-being is limited to the time that employees are at work, and careful strategies are developed to manage working hours and associated workload. However, with increasing technological advances many employees are 'taking their work home with them' (e.g., PDA's and access to emails at home). This may make the boundary between work and non-work time much more difficult for individuals to establish, resulting in compromised space for recovery activities and processes to take place. While there are undoubtedly some roles in any organisation which are critical and require individuals to work at times outside of their allotted hours; many organisations use the promise of constant connectivity as an incentive, with PDA's and company mobile technology offered as a perk of promotion. Perhaps if fewer individuals were constantly connected to their work outside of their working hours, more opportunity for recovery would be created (Cropley \& Millward, 2009).

\section{Directions for future research}

There are a number of avenues worthy of exploration through future research. Firstly, it would be interesting to explore further the link between work-related affective rumination and clinical rumination. Can they be considered the same construct in terms of neurocognitive processing? Furthermore, clinical rumination is often characterised as a trait tendency; as such, it would be of interest to explore the stability of work-related rumination over time. Also of interest is the link between ruminative style and personality constructs, and the stability of ruminative style. Research suggests that individuals vary their personality across different social contexts (Querstret \& Robinson, in press); and it would be of interest to assess whether individuals vary their ruminative style across different stress contexts. As this research appears to suggest that it is not rumination per se, but type of rumination, that is implicated in compromised well-being; it would be interesting to develop and test interventions designed to help those who ruminate affectively to adopt a more problem-solving focus. Furthermore, exploration of the different brain regions involved in different work-related ruminative states would be very useful. Finally, it would be of interest to carry out longitudinal research to see if acute fatigue sufferers develop chronic fatigue without intervention.

\section{Limitations}

The most significant limitation of this study is its cross-sectional nature which means that establishing causation related to the relationship between variables is not possible. Another limitation is the self-report nature of the data, which could have inflated the associations between variables through common method variance (Podsakoff, MacKenzie, 
Lee, \& Podsakoff, 2003). However, this should have been minimised because the measures included on the questionnaire spanned a variety of different constructs; and scales were varied to minimise the chance that individuals would simply respond "by rote" (Podsakoff et al., 2003). A further potential limitation of the study was that it was essentially limited to those subjects with Internet connectivity which could potentially bias the sample in favour of higher sociodemographic groups. However, The Office of National Statistics (ONS, 2011) reported that the penetration of Internet connectivity is approximately in the order of $77 \%$ within the UK, and connectivity is not confined to the more economically affluent or specific ethnic groups.

The occupational characteristics of the sample suggests a bias toward occupations that are inherently more psychologically stressful; however, as we were interested in rumination, and rumination is reported to be more prevalent in workers with psychologically demanding roles (Pravettoni et al., 2007), this was not considered a detriment. Finally, it could be that the sample showed a distribution skew as a result of "volunteer bias" whereby individuals suffering greater levels of fatigue might be less willing to participate; however, it could also be argued that workers who were more fatigued may be more willing to participate due to being personally invested in the subject matter (Winwood et al., 2007). Furthermore, the study was presented as an exploration into the factors that interfered with an individual's ability to adequately recover outside of their working days, and there was no direct reference to fatigue in the study information.

The study limitations are offset by some considerable strengths. Firstly, the large sample size $(\mathrm{N}=719)$ had an almost equal gender split, and was comprised of participants representing a broad cross-section of industry sectors. Furthermore, the novel findings of this study extend our understanding of the mechanisms by which work-related stress may be translated into ill-health via inadequate recovery; and highlight some interesting future directions for research in this area.

\section{Conclusions}

The major finding in this study was that affective rumination appears more detrimental to recovery processes than problem-solving pondering. Specifically, it appears to be the emotional component which seems to be problematic. In the context of identifying mechanisms by which demands of work are translated into ill-health, this appears to be a key finding. The finding that problem-solving pondering may be less detrimental to recovery suggests that it is the type of rumination, not rumination per se, which is important. Therefore, strategies to help affective ruminators engage in a more problemsolving focussed rumination style could be very effective. 


\section{References}

Akerstedt, T., Fredlund, P., Gillberg, M., \& Jansson, B. (2002). Work Load and Work Hours in Relation to Disturbed Sleep and Fatigue in a Large Representative Sample. Journal of Psychosomatic Research, 53, 585-588.

Akerstedt, T., Knutsson, A., Westerholm, P., Theorell, T., Alfredsson, L., \& Kecklund, G. (2004). Mental Fatigue, Work and Sleep. Journal of Psychosomatic Research, 57, 427-433.

Baron, R. M., \& Kenny, D. A. (1986). The moderator-mediator variable distinction in social psychological research: Conceptual, strategic and statistical considerations. Journal of Personality and Social Psychology, 51, 1173-1182.

Berset, M., Elfering, A., Luthy, S., Luthi, S., Semmer, N. K. (2010). Work Stressors and Impaired Sleep: Rumination as a Mediator. Stress and Health, accessed 9/07/10 http://onlinelibrary.wiley.com/doi/10.1002/smi.1337/pdf

Brief, A. P., Burke, M. J., George, J. M., Robinson, B. S., \& Webster, J. (1988). Should Negative Affectivity remain an unmeasured Variable in the Study of Job Stress? Journal of Applied Psychology, 73, 193-198.

Brosschot, J. F., Gerin, W., \& Thayer, J. F. (2006). The Perseverative Cognition Hypothesis: A Review of Worry, Prolonged Stress-Related Physiological Activation and Health. Journal of Psychosomatic Research, 60, 113-124.

Brosschot, J. F., Van Dijk, E., \& Thayer, J.F. (2007). Daily Worry is related to slow Heart Rate Variability during Waking and the Subsequent Nocturnal Sleep Period. International Journal of Psychophysiology, 63, 39-47.

Bultmann, U., Kant, I. J., van den Brandt, P. A., \& Kasl, S. V. (2002). Psychosocial Work Characteristics as Risk Factors for the onset of Fatigue and Psychological Distress: Prospective Results from the Maastrich Cohort study. Psychological Medicine, 32, 333-345.

Bultmann, U., Kant, I., van Amelsvoort, L.G., van den Brandt, P.A., \& Kasl, S.V. (2001). Differences in Fatigue and Psychological Distress across Occupations: Results from the Maastricht Cohort Study of fatigue at work. Journal of Occupational and Environmental Medicine, 43. 979-983.

Bultmann, U., Kant, I., van Amelsvoort, L. G. P. M., \& Kasl, S. V. (2001). Differences in Fatigue and Psychological Distress Across Occupations: Results from the Maastrich Cohort Study of Fatigue at Work. Journal of Environmental Medicine, 43, 976-983.

Buysse, D. J., Reynolds III, C. F., Monk, T. H., Berman, S. R., \& Kupfer, D. J. (1988). The Pittsburgh Sleep Quality Index: A New Instrument for Psychiatric Practice and Research. Psychiatry Research, 28, 193-213.

Caldwell, J. A., \& Caldwell, J. L., (2005). Fatigue in Military Aviation: An Overview of U.S. Military-Approved Pharmacological Countermeasures. Aviation, Space and Environmental Medicine, 76, C39-C51.

Carpenter, J. S., \& Andrykowski, M. A. (1998). Psychometric Evaluation of the Pittsburgh Sleep Quality Index. Journal of Psychosomatic Research, 45, 5-13. 
Chen, M. K. (1986). The Epidemiology of self-perceived Fatigue among Adults. Preventive Medicine, 15, 74-81.

Cohen, J., \& Cohen, P. (1975). Applied Multiple Regression and Correlation Analysis for the Behavioural Sciences. Hillsdale, New Jersey: Lawrence Erlbaum Associates.

Cropley, M., Dijk, D., \& Stanley, N. (2006). Job strain, Work Rumination, and Sleep in School Teachers. European Journal of Work and Organisational Psychology, 15, 181-196.

Cropley, M., Michalianou, G. Pravettoni, G,. \& Millward, L. (2012). The relation of post work ruminative thinking with eating behaviour. Stress and Health, 28, 23-30.

Cropley, M., \& Millward, L. J. (2009). How do Individuals 'switch-off' from Work during Leisure? A Qualitative Description of the Unwinding Process in High and Low Ruminators. Leisure Studies, 28, 333-347.

Cropley, M. \& Zijlstra, F. R. H. (2011). Work and Rumination. In Langan-Fox, J \& Cooper, C.L. (Eds). Handbook of Stress in the Occupations. Edward Elgar Publishing Ltd., U.K

Dawson, D., Noy, Y. I., Harma, M., Akerstedt, T., \& Belenky, G. (2011). Modelling fatigue and the use of Fatigue Models in Work Settings. Accident Analysis and Prevention, 43, 549-564.

De Croon, E. M., Sluiter, J., \& Frings-Dresen, M. H. W. (2003). Need for Recovery after Work Predicts Sickness Absence: a 2 Year Prospective Cohort Study in Truck Drivers. Journal of Psychosomatic Medicine, 55, 331-339.

De Lange, A. H., Taris, T. W., Kompier, M. A. J., Houtman, I. L. D., \& Bongers, P.M. (2003). The very best of the millennium: Longitudinal research on the Job Demands-Control model. Journal of Occupational Health Psychology, 8, 282-305.

Etzion, D., Eden, D., \& Lapidot, Y. (1998). Relief from Job Stressors and Burnout: Reserve Service as a Respite. Journal of Applied Psychology, 83, 577-585.

Felstead, A., Gallie, D., \& Green, F. (2002). Work skills in Britain 1986-2001. Nottingham: DfES Publications.

Field, A. (2009). Discovering Statistics Using SPSS (3rd ed.). London: Sage Publications Ltd.

Folkard, S., \& Tucker, P. (2003). Shift Work, Safety and Productivity. Occupational Medicine, 53, 95-101.

Fritz, C., Sonnentag, S., Spector, P. E., \& McInroe, J. A. (2010). The Weekend Matters: Relationships between Stress Recovery and Affective Experiences. Journal of Organisational Behaviour, 31, 1137-1162.

Gallie, D., White, M., Cheng, Y. \& Tomlinson, M. (1998). Restructuring the Employment Relationship. OUP: Oxford.

Hardy, G. E., Shapiro, D. A., \& Borrill, C. S. (1997). Fatigue in the Workforce of National Health Service Trusts: Levels of Symptomatology and links with Minor Psychiatric Disorder, Demographic, Occupational and Work Role Factors. Journal of Psychosomatic Research, 43, 83-92. 
Harrison, Y. \& Horne, J. A. (1999). One Night of Sleep loss impairs Innovative Thinking and Flexible Decision Making. Organisational Behaviour and Human Decision Processes, 78, 128-145.

Harvey, A. G., Tang, N. K., \& Browning, L. (2005). Cognitive Approaches to Insomnia. Clinical Psychology Review, 25, 593-611.

Hazlett, R. L., \& Haynes, S. N. (1992). Fibromyalgia: A time-series Analysis of the Stress or Physical Symptom Association. Journal of Behavioural Medicine, 15, 541-558.

Hobfoll, S. E. (1998). Stress, culture, and community: The psychology and physiology of stress. New York: Plenum Press.

Houtman, I. L. D. (1997). Trends in Work and Health. Amsterdam: NIA/TNO.

Judd, C. M., \& Kenny, D. A. (1981). Process analysis: Estimating mediation in treatment evaluations. Evaluation Review, 5, 602-619.

Kantermann, T., Juda, M., Vetter, C., \& Roenneberg, T. (2010). Shift-Work Research: Where do we Stand, Where should we go? Sleep and Biological Rhythms, 8, 95105.

Karasek, R., Brisson, C., Kawakami, N., Houtman, I., Bongers, P., \& Amick, B. (1988). The Job Content Questionnaire (JCQ): An Instrument for Internationally Comparative Assessments of Psychosocial Job Characteristics. Journal of Occupational Health Psychology, 3, 322-355.

Karasek, R. \& Theorell, T. (1990). Healthy Work: Stress, Productivity, and the Reconstruction of Working Life. Basic Books, New York.

Kecklund, G., \& Akerstedt, T. (2004). Apprehension of the Subsequent Working day is Associated with a Low Amount of Slow Wave Sleep. Biological Psychology, 66, 169176.

Kortte, K. B., Gilbert, M., Gorman, P., \& Wegener, S. T. (2010). Positive Psychological Variables in the Prediction of Life Satisfaction after Spinal Cord Injury. Rehabilitation Psychology, 55, 40-47.

Kunert, K., King, L., \& Kolkhorst, F. W. (2007). Fatigue and Sleep Quality in Nurses. Journal of Psychosocial Nursing, 45, 31-37.

Kuper, H., \& Marmot, M. (2003). Job Strain, Job Demands, Decision Latitude, and Risk of Coronary Heart Disease within theWhitehall II Study. Journal of Epidemiology and Community Health (1979-), 57, 147-153.

Lauber, J. K., \& Kayten, P. J. (1988). Sleepiness, Circadian Dysrhythmia, and Fatigue in Transportation System Accidents. Sleep, 11, 503-12.

Loge, J. H., Ekeberg, O., \& Kaasa, S. (1998). Fatigue in the General Norwegian Population: Normative Data and Associations. Journal of Psychosomatic Research, $45,53-65$.

Lyubomirsky, S., Caldwell, N. D., \& Nolen-Hoeksema, S. (1998). Effects of Ruminative and Distracting Responses to Depressed Mood on Retrieval of Autobiographical Memories. Journal of Personality and Social Psychology, 75, 166-177.

Lyubomirsky, S., Kasri, F., \& Zehm, K. (2003). Dysphoric Rumination Impairs Concentration on Academic Tasks. Cognitive Therapy and Research, 27, 309-330. 
Lyznicki, J. M., Doege, T. C., Davis, R. M., \& Williams, M. A. (1998). Sleepiness, Driving, and Motor Vehicle Crashes. Journal of the American Medical Association, 279, 19081913.

Martin, L. L., \& Tesser, A. (1996). Some Ruminative Thoughts. In R. S. Wyer, Jr. (Ed.), Advances in Social Cognition (Vol. IX, pp. 1-47). Hillsdale, NJ: Lawrence Erlbaum Associates, Inc.

McEwen, B. S. (1998). Stress, adaptation, and Disease: Allostasis and Allostatic Load. Annals of the New York Academy of Sciences, 840, 33-44.

Meijman, T. F., \& Mulder, G. (1998). Psychological Aspects of Workload. In P. J. D. Drenth, H. Thierry, \& C. J. W. de (Eds.), Handbook of work and organizational psychology (Vol. 2, pp. 5-33). Hove, England: Psychology Press.

Mellings, T. M., \& Alden, L. E. (2000). Cognitive Processes in Social Anxiety: The Effects of Self-focus, Rumination and Anticipatory Pprocessing. Behaviour Research and Therapy, 38, 243-257.

Miller, R. G. (1984). Simultaneous statistical inference (2nd ed.). New York: Springer, Yerlag.

Nylen, L., Melin, B., \& Laflamme, L. (2007). Interference between Work and Outside-Work Demands Relative to Health: Unwinding Possibilities among Full-Time and PartTime Employees. International Journal of Behavioural Medicine, 14, 229-236.

O'Connor, P. J., \& Youngstedt, S. D. (1995). Influence of Exercise on Human Sleep. Exercise and Sport Sciences Reviews, 23, 105-134.

Office for National Statistics (2011). Internet Access - Households and Individuals, 2011. Accessed, 31 August 2011. http://www.ons.gov.uk/ons/

dcp171778_227158.pdf

Ottaviano, C., Shapiro, D., DDavydov, D. M., Goldstein, I. B., \& Mills, P. J. (2009). The Autonomic Phenotype of Rumination. International Journal of Psychophysiology, 72, 267-275.

Pandey, W., \& Elliott, S. (2010). Suppressor Variables in Social Work Research: Ways to Identify in Multiple Regression Models. Journal of the Society for Social Work and Research, 1, 28-40.

Podsakoff, P. M., MacKenzie, S. B., Lee, J. Y., \& Podsakoff, N. P. (2003). Common Method Biases in Behavioral Research: A Critical Review of the Literature and Recommended Remedies. Journal of Applied Psychology, 88, 879903.

Porkka-Heiskanen, T., Kalinchuk, A., Alanko, L., Urrila, A., \& Stenberg, D. (2003). Adenosine, energy metabolism, and sleep. The Scientific World Journal, 3, 790798.

Pravettoni, G., Cropley, M., Leotta, S. N., \& Bagnara, S. (2007). The Differential Role of Mental rumination among Industrial and Knowledge Workers. Ergonomics, 50, 1931-1940.

Querstret, D. (2011). A Hard Days Night: when was the last time you Relaxed? NursingTimes.net, Retrieved from: http://www.nursingtimes.net/nursing- 
practice/clinical-specialisms/management/a-hard-days-night-when-was-the-lasttime-you-relaxed/5025717.article

Querstret, D., \& Cropley, M. (2011). Why nurses need to recover after work. Nursing Times, 107, 14-17.

Querstret, D., \& Robinson, O. C. (in press). Person, Persona and Personality Modification: An In-depth Qualitative Exploration of Quantitative Findings. Qualitative Research in Psychology.

Roger, D., \& Jamieson, J. (1988). Individual Differences in Delayed Heart-rate Recovery Following Stress: The Role of Extraversion, Neuroticism and Emotional Control. Personality and Individual Differences, 9, 721-726.

Rogers, N. L., Szuba, M. P., Staab, J. P., Evans, D. L. \& Dinges, D. F. (2001). Neuroimmunologic Aspects of Sleep and Sleep Loss. Seminars in Clinical Neuropsychiatry, 6, 295-307.

Rydstedt, L. W., Cropley, M., Devereux, J., \& Michalianou, G. (2009). The Effects of Gender, Long-Term Need for Recovery and Trait-Inhibition-Ruimination on Morning and Evening Saliva Cortisol Secretion. Anxiety, Stress \& Coping, 22, 465-474.

Sarason, I. G., Pierce, G. R., \& Sarason, B. R. (Eds.). (1996). Cognitive interference: Theories, Methods, and Findings. Hillsdale, NJ: Erlbaum, Inc.

Schwartz, S., Anderson, W. M., Cole, S. R., Cornoni-Huntley, J., Hays, J.C., \& Blazer, D. (1999). Insomnia and Heart Disease: A Review of Epidemiologic Studies. Journal of Psychosomatic Research, 47, 313-333.

Segerstrom, S. C., Stanton, A. L., Alden, L. E., \& Shortridge, B. E. (2003). A Multidimensional Structure for Repetitive Thought: What's on your mind, and how, and how much? Journal of Personality and Social Psychology, 85, 909-921.

Seo, M. G., Barrett, L. F., \& Bartunek, J. M. (2004). The role of Affective Experience in Work Motivation. Academy of Management Review, 29, 423-439.

Singh, N. A., Clements, K. M., \& Fiatarone, M. A. (1997). A Randomized Controlled Trial of the Effect of Exercise on Sleep. Sleep, 20, 95-101.

Sluiter, J. K, de Croon, E. M., Meijman, T. F., \& Frings-Dresen, M. H. (2003). Need for Recovery from Work-Related Fatigue and its Role in the Development and Prediction of Subjective Health Complaints. Occupational and Environmental Medicine, 60(Suppl 1), i62-i70.

Sluiter, J. K., van der Beek, A. J., \& Frings-Dresen, M. H. W. (1999). The Influence of Work Characteristics on the Need for Recovery and Experienced Health: A study on Coach Drivers. Ergonomics, 42, 573-583.

Sonnentag, S. \& Fritz, C. (2007). The Recovery Experience Questionnaire: Development and Validation of a Measure for Assessing Recuperation and Unwinding from Work. Journal of Occupational Health Psychology, 12, 204-221.

SPSS. (2009). PASW Statistics 18, Release Version 18.0.0. Chicago, IL, www.spss.com.

Stajkovic, A. D., \& Luthans, F. (1998). Self-efficacy and Work-Related Performance: A Meta-Analysis. Psychological Bulletin, 124, 240-261. 
Stewart, D., Abbey, S., Meana, M., \& Boydell, K. M. (1998). What makes Women Tired? A Community Sample. Journal of Womens Health, 7, 69-76.

Suadicani, P., Hein, H.O., \& Gyntelberg, F. (1993). Are Social Inequalities as Associated with the Risk of Ischemic-Heart-Disease a Result of Psychosocial WorkingConditions. Atherosclerosis, 101, 165-175.

Taylor, D. J., Mallory, L. J., Lichstein, K. L., Durrence, H. H., Riedel, B. W., \& Bush, A. J. (2007). Comorbidity of Chronic Insomnia with Medical Problems. Sleep, 30, 213218.

Thomsen, D. K., Mehlsen, M. Y., Christensen, S., \& Zachariae, R. (2003). RuminationRelationship with Negative Mood and Sleep Quality. Personality and Individual Differences, 34, 1293-1301.

Thomsen, D. K., Mehlsen, M. Y., Hokland, M., Viidik, A., Olesen, F., Avlund, K., Munk, K., \& Zachariae, R. (2004). Negative Thoughts and Health: Associations among Rumination, Immunity, and Health Care Utilization in a Young and Elderly Sample. Psychosomatic Medicine, 66, 363-371.

Van der Doef, M. P., \& Maes, S. (1999). The Job Demand - Control (- Support) Model and psychological well-being: A review of 20 years of empirical research. Work and Stress, 13, 87-114.

Van Veldhoven, M. J. P. M., \& Sluiter, J. K. (2009). Work-related recovery opportunities: Testing Scale Properties and Validity in Relation to Health. International Archives of Occupational and Environmental Health, 82, 1065-1075. doi: 10.1007/s00420-0090411-z

Van't Leven, M., Zielhuis, G. A., van der Meer, J. W., Verbeek, A. L., \& Bleijenberg, G. (2009). Fatigue and Chronic Fatigue Syndrome-like Complaints in the General Population. European Journal of Public Health, 20, 251-257.

Watson, D., Clark, L., \& Tellegen, A. (1988). Development and Validation of brief Measures of Positive and Negative Affect: The PANAS scales. Journal of Personality and Social Psychology, 54, 1063-1070.

Winwood, P. C., Bakker, A. B., \& Winefield, A. H. (2007). An Investigation of the Role of Non-work-time Behaviour in Buffering the Effects of Work Strain. Journal of Occupational and Environmental Medicine, 49, 862-871.

Winwood, P. C., Lushington, K., \& Winefield, A. H. (2006). Further Development and Validation of the Occupational Fatigue Exhaustion Recovery (OFER) scale. Journal of Occupational and Environmental Medicine, 48, 381-389.

Winwood, P. C., Winefield, A. H., Dawson, D., \& Lushington, K. (2005). Development and Validation of a Scale to Measure Work-Related Fatigue and Recovery: the Occupational Fatigue Exhaustion Recovery scale (OFER). Journal of Occupational and Environmental Medicine, 47, 594-606.

Williamson, A., Lombardi, D.A., Folkard, S., Stutts, J., Courtney, T.K., \& Connor, J., (2011). The Links between Fatigue and Safety. Accident Analysis and Prevention, 43, 498-515. 
Zhao, X., Lynch Jr., J. G., \& Chen, Q. (2010). Reconsidering Baron \& Kenny: Myths and Truths about Mediation Analysis. Journal of Consumer Research, 37, 197-206.

Zoccola, P. M., Dickerson, S. S., \& Lam, S. (2009). Rumination Predicts longer Sleep Onset Latency after an Acute Ppsychosocial Stressor. Psychosomatic Medicine, 71, 771-775. 
TABLE 1

Means, standard deviations and ranges for study measures

Measure

1. Affective rumination

2. Problem-solving pondering

3. Detachment

4. Chronic fatigue

5. Acute fatigue

6. Sleep quality

\section{Mean}

11.42

14.82

15.88

40.44

53.50

7.05

\section{SD}

3.56

3.62

4.52

27.01

26.39

4.09

0-100

$0-21$

Study measures: 1. Affective rumination, 2. Problem-solving pondering, 3. Detachment (WorkRelated Rumination Scale); 4. Chronic fatigue, 5. Acute fatigue (Occupational Fatigue Exhaustion Recovery scale); 6. Sleep quality (Pittsburgh Sleep Quality Index).

FIGURE 1: Simple mediation model

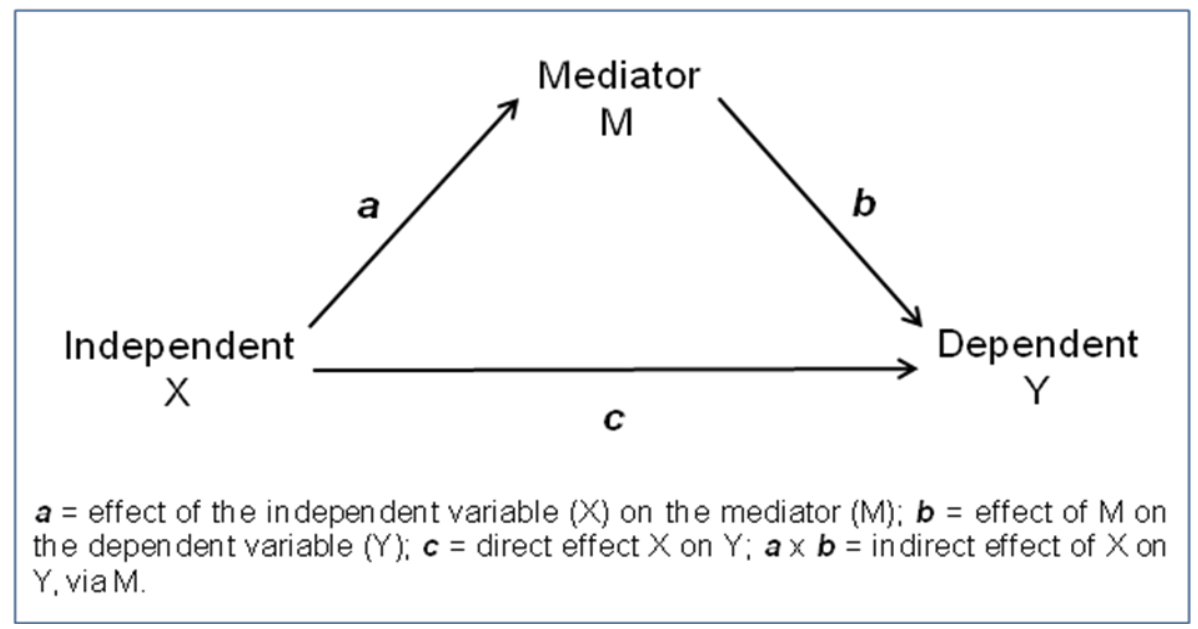


TABLE 2

Zero order correlations for all study variables

\begin{tabular}{|c|c|c|c|c|c|c|c|c|c|c|c|c|c|c|c|}
\hline Variables & 1 & 2 & 3 & 4 & 5 & 6 & 7 & 8 & 9 & 10 & 11 & 12 & 13 & 14 & 15 \\
\hline 1. Age & - & & & & & & & & & & & & & & \\
\hline 2. Work status & -.036 & - & & & & & & & & & & & & & \\
\hline 3. Hours worked per week & .058 & $-.179 *$ & - & & & & & & & & & & & & \\
\hline 4. Dependent children & $-.196 *$ & -.071 & -.042 & - & & & & & & & & & & & \\
\hline 5. Gender & .108 & -.107 & $.323 *$ & $-.109^{b}$ & - & & & & & & & & & & \\
\hline 6. Negative affect & $-.176 *$ & .028 & -.019 & .004 & $-.247 *$ & - & & & & & & & & & \\
\hline 7. Job demands & -.029 & .062 & $.200 *$ & -.046 & $-.164 *$ & $.161 *$ & - & & & & & & & & \\
\hline 8. Job control & .043 & $.186 *$ & -.027 & -.036 & $-.143 *$ & $-.123^{\mathrm{a}}$ & $.271 *$ & - & & & & & & & \\
\hline 9. Recovery opportunities & .011 & $.152 *$ & $-.239 *$ & .027 & $-.242 *$ & $-.115 *$ & -.015 & $.704 *$ & - & & & & & & \\
\hline 10. Affective rumination & $-.097 *$ & .008 & $.121 *$ & .057 & $-.167 *$ & $.508 *$ & $.265 *$ & $-.158 *$ & $-.292 *$ & - & & & & & \\
\hline 11. Problem-solving pondering & -.056 & .089 & $.149 *$ & -.030 & $-.124 *$ & $.313 *$ & $.480 *$ & $.124 *$ & -.076 & $.586 *$ & - & & & & \\
\hline 12. Detachment & .029 & -.034 & $-.161 *$ & .021 & $.154 *$ & $-.389 *$ & $-.381 *$ & .055 & $.219 *$ & $-.712 *$ & $-.664 *$ & - & & & \\
\hline 13. Chronic fatigue & -.047 & -.044 & .051 & .081 & $-.147 *$ & $.487 *$ & .088 & $-.340 *$ & $-.368 *$ & $.628 *$ & $.246 *$ & $-.441 *$ & - & & \\
\hline 14. Acute fatigue & -.024 & -.052 & .056 & -.010 & $-.139 *$ & $.416 *$ & $.160 *$ & $-.317 *$ & $-.378 *$ & $.533 *$ & $.254 *$ & $-.443 *$ & $.712 *$ & - & \\
\hline 15. Sleep quality & .005 & -.003 & -.030 & .020 & -.050 & $.402 *$ & -.027 & $-.265 *$ & $-.270 *$ & $.376 *$ & $.140 *$ & $-.303 *$ & $.433^{*}$ & $.431 *$ & - \\
\hline
\end{tabular}

Bonferroni statistic applied; ${ }^{*} \mathbf{p}<. \mathbf{0 0 1} ;{ }^{a} \mathrm{p}=.001,{ }^{b} \mathrm{p}=.004$

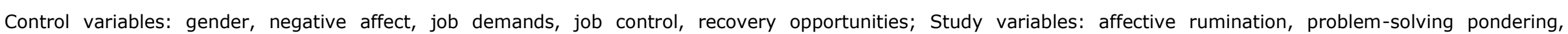
detachment, chronic fatigue, acute fatigue, sleep quality. 
TABLE 3

Results from multiple regression analysis predicting chronic fatigue

\begin{tabular}{lcccc}
\hline & \multicolumn{2}{c}{ Step 1} & \multicolumn{2}{c}{ Step 2} \\
\cline { 2 - 5 } & Beta & $t$ & Beta & $t$ \\
\hline 1. Gender & -.122 & $-3.743 * * *$ & -.070 & $-2.421 *$ \\
2. Negative affect & .404 & $12.676 * * *$ & .189 & $5.954 * * *$ \\
3. Job demands & .038 & 1.121 & .008 & 0.258 \\
4. Job control & -.141 & $-3.033 * *$ & -.141 & $-3.449 * *$ \\
5. Recovery opportunities & -.251 & $-5.467 * * *$ & -.096 & $-2.316 *$ \\
6. Affective rumination & & & .486 & $11.478 * * *$ \\
7. Problem-solving pondering & & & -.153 & $-3.942 * * *$ \\
8. Detachment & & & -.054 & -1.288 \\
9. Sleep quality & & & .102 & $3.532 * * *$ \\
Adjusted $R^{2}$ & & .354 & & .509 \\
$F$ & & $79.742 * * *$ & & $83.553 * * *$ \\
$\Delta R^{2}$ & & .359 & & .515 \\
$F$ & & $79.742 * * *$ & & $57.000 * * *$ \\
\hline$* p<.05 * * p<.01, * * * p<.001 . C 0 n s t a n t: s t e p$ & & & & \\
\hline
\end{tabular}

$* p<.05, * * p<.01, * * * p<.001$. Constant: step $1=46.977$, step $2=30.584$

Control variables: 1. Gender, 2. Negative affect, 3. Job demands, 4. Job control 5. Recovery opportunities; Study measures: 6. Affective rumination, 7. Problem-solving pondering, 8. Detachment; 9. Sleep quality. 
TABLE 4

Results from multiple regression analysis predicting acute fatigue

\begin{tabular}{|c|c|c|c|c|}
\hline & \multicolumn{2}{|c|}{ Step 1} & \multicolumn{2}{|c|}{ Step 2} \\
\hline & Beta & $t$ & Beta & $t$ \\
\hline 1. Gender & -.127 & $-3.757 * * *$ & -.086 & $-2.751 * *$ \\
\hline 2. Negative affect & .317 & $9.613 * * *$ & .138 & $4.007 * * *$ \\
\hline 3. Job demands & .121 & $3.459 * *$ & .090 & $2.560 * *$ \\
\hline 4. Job control & -.134 & $-2.782 * *$ & -.134 & $-3.005 * *$ \\
\hline 5. recovery opportunities & -.276 & $-5.834 * * *$ & .144 & $-3.182 * *$ \\
\hline 6. Affective rumination & & & .276 & $5.989 * * *$ \\
\hline 7. Problem-solving pondering & & & -.122 & $-2.900 * *$ \\
\hline 8. Detachment & & & -.144 & $-3.150 * *$ \\
\hline 9. Sleep quality & & & .163 & $5.194 * * *$ \\
\hline Adjusted $R 2$ & & .311 & & .416 \\
\hline$F$ & & $65.779 * * *$ & & 57.722 \\
\hline$\Delta R 2$ & & .174 & & .251 \\
\hline$F$ & & $65.779 * * *$ & & $35.926 * * *$ \\
\hline
\end{tabular}

${ }^{*} p<.05,{ }^{*} * p<.01, * * * p<.001$. Constant: step $1=50.214$, step $2=55.161$

Control variables: 1. Gender, 2. Negative affect, 3. Job demands, 4. Job control, 5. Recovery opportunities; Study variables: 6. Affective rumination, 7. Problem-solving pondering, 8. Detachment, 9. Sleep quality. 
TABLE 5

The mediating effect of sleep quality on the relationship between affective rumination and $C F$, and affective rumination and $A F$

\begin{tabular}{|c|c|c|c|c|c|c|}
\hline & \multicolumn{2}{|c|}{ Step 1} & \multicolumn{2}{|c|}{ Step 2} & \multicolumn{2}{|c|}{ Step 3/4 } \\
\hline & Beta & $t$ & Beta & $t$ & Beta & $t$ \\
\hline \multicolumn{7}{|l|}{ Chronic fatigue (CF) } \\
\hline Affective rumination & .628 & $21.634^{*}$ & .376 & $10.879 *$ & .543 & $17.967^{*}$ \\
\hline Sleep quality & & & & & .228 & $7.563 *^{a}$ \\
\hline \multicolumn{7}{|l|}{ Acute fatigue ( $A F$ ) } \\
\hline Affective rumination & .533 & $16.873 *$ & .376 & $10.879 *$ & .432 & $13.250 *$ \\
\hline Sleep quality & & & & & .268 & $8.209 * a$ \\
\hline
\end{tabular}

${ }^{*} \mathrm{p}<.001 ;{ }^{a}$ partial mediation effect

Step 1: outcome=chronic fatigue/acute fatigue, predictor=affective rumination; Step 2: outcome=affective rumination, predictor=sleep quality; Step 3: outcome=chronic fatigue/acute fatigue, predictor=sleep quality, affective rumination. 
TABLE 6

The mediating effect of sleep quality on the relationship between problem-solving pondering and chronic fatigue, and problem-solving pondering and acute fatigue

\begin{tabular}{|c|c|c|c|c|c|c|}
\hline & \multicolumn{2}{|c|}{ Step 1} & \multicolumn{2}{|c|}{ Step 2} & \multicolumn{2}{|c|}{ Step 3/4 } \\
\hline & Beta & $t$ & Beta & $t$ & Beta & $t$ \\
\hline \multicolumn{7}{|l|}{ Chronic fatigue } \\
\hline Problem-solving pondering & .246 & $6.804^{*}$ & .140 & $3.782 *$ & .190 & $5.694 *$ \\
\hline Sleep Quality & & & & & .406 & 12.199* \\
\hline \multicolumn{7}{|l|}{ Acute fatigue } \\
\hline Problem-solving pondering & .254 & $7.040 *$ & .140 & $3.782 *$ & .198 & $5.952 *$ \\
\hline Sleep Quality & & & & & .403 & $12.115^{*}$ \\
\hline
\end{tabular}

$* \mathrm{p}<.001$

Step 1: outcome=chronic fatigue/acute fatigue, predictor=problem-solving pondering; Step 2: outcome=sleep quality, predictor=problem-solving pondering; Step 3: outcome=chronic fatigue/acute fatigue, predictor=sleep quality, problem-solving pondering. 